\title{
Long-term trends in pancreatic cancer mortality in Spain (1952-2012)
}

Daniel Seoane-Mato ${ }^{1}$, Olivier Nuñez ${ }^{2,3}$, Nerea Fernández-de-Larrea ${ }^{2,3}$, Beatriz Pérez-Gómez ${ }^{2,3}$, Marina Pollán²,3, Gonzalo López-Abente ${ }^{2,3}$ and Nuria Aragonés ${ }^{2,3^{*}}$ (D)

\begin{abstract}
Background: Pancreatic cancer is acquiring increasing prominence as a cause of cancer death in the population. The purpose of this study was to analyze long-term pancreatic cancer mortality trends in Spain and evaluate the independent effects of age, death period and birth cohort on these trends.

Methods: Population and mortality data for the period 1952-2012 were obtained from the Spanish National Statistics Institute. Pancreatic cancer deaths were identified using the International Classification of Diseases ICD-6 to ICD-9 (157 code) and ICD-10 (C25 code). Age-specific and age-adjusted mortality rates were computed by sex, region and five-year period. Changes in pancreatic cancer mortality trends were evaluated using joinpoint regression analyses by sex and region. Age-period-cohort log-linear models were fitted separately for each sex, and segmented regression models were used to detect changes in period- and cohort-effect curvatures.

Results: In men, rates increased by $4.1 \%$ per annum from 1975 until the mid-1980s and by $1.1 \%$ thereafter. In women, there was an increase of 3.6\% per annum until the late 1980s, and 1.4\% per annum from 1987 to 2012. With reference to the cohort effects, there was an increase in mortality until the generations born in the 1950s in men and a subsequent decline detected by the change point in 1960. A similar trend was observed in women, but the change point occurred 10 years later than in men.

Conclusions: Pancreatic cancer mortality increased over the study period in both sexes and all regions. An important rise in rates -around 4\% annually- was registered until the 1980s, and upward trends were more moderate subsequently. The differences among sexes in trends in younger generations may be linked to different past prevalence of exposure to some risk factors, particularly tobacco, which underwent an earlier decrease in men than in women.
\end{abstract}

Keywords: Pancreatic cancer, Tobacco smoking, Mortality, Age-period-cohort analysis, Change-points, Time trends, Spain

\section{Background}

Though, in terms of incidence, pancreatic cancer is not among the most frequent cancers, its high lethality places this malignant tumor among those that cause a higher number of deaths worldwide [1]. The overall prognosis of pancreatic cancer is extremely poor, with five-year relative survival rates around 6\% in Europe [2].

In Spain, 6367 new pancreatic cancer cases were estimated to occur in 2012, with age adjusted incidence rates (European standard population) of 11.5 cases per 100,000

\footnotetext{
* Correspondence: nuria.aragones@salud.madrid.org

${ }^{2}$ Cancer and Environmental Epidemiology Unit, National Center for Epidemiology, Carlos III Institute of Health, Madrid, Spain

${ }^{3}$ Consortium for Biomedical Research in Epidemiology and Public Health

(CIBER Epidemiología y Salud Pública, CIBERESP), Madrid, Spain

Full list of author information is available at the end of the article
}

males and 7.6 cases per 100,000 females [1]. According to these data, this cancer has become the tenth most common cancer type registered among men and the sixth among women.

As regards to mortality, in 2012 pancreatic cancer ranked seventh as cause of cancer death among Spanish men, with age adjusted mortality rates of 10.7 per 100,000 inhabitants [3], being the third leading cause of oncologic deaths among men between 40 and 59 years [4]. In women, pancreatic cancer was the fourth most common cause of oncologic death, with rates around 6.8 per 100,000 . In sum, pancreatic cancer is currently responsible for 5 and $7 \%$ of the total number of deaths due to cancer among Spanish males and females, respectively.

(c) The Author(s). 2018 Open Access This article is distributed under the terms of the Creative Commons Attribution 4.0 International License (http://creativecommons.org/licenses/by/4.0/), which permits unrestricted use, distribution, and reproduction in any medium, provided you give appropriate credit to the original author(s) and the source, provide a link to the Creative Commons license, and indicate if changes were made. The Creative Commons Public Domain Dedication waiver (http://creativecommons.org/publicdomain/zero/1.0/) applies to the data made available in this article, unless otherwise stated. 
The etiology of pancreatic cancer is unclear [5] and, as in other cancers, probably multifactorial. Several factors have been suggested as possible causes for this neoplasm, but their contribution, according to their relative risks, is small [6]. Between 3 and 7\% of cases could be associated with genetic susceptibility. Regarding exogenous exposures, tobacco smoking (with strong evidence) and Helicobacter pylori infection (with moderate evidence) have been considered the major risk factors for pancreatic cancer, in terms of their population attributable fraction, in a recent review [6]. According to the American Institute for Cancer Research, there is also convincing evidence to consider body fatness as a risk factor for pancreatic cancer [7]. Other exposures or clinical entities that have been suggested to be associated with increased risk include high red meat consumption, type II Diabetes Mellitus, chronic pancreatitis, high alcohol consumption, hepatitis B virus infection and specific occupational exposures, such as certain pesticides, organic solvents, polycyclic aromatic hydrocarbons and nickel compounds [6-9]. On the other hand, several factors could have a preventive effect, as it is the case of allergic conditions, high fruit and vegetable consumption and physical activity [6-8].

This study aimed to monitor pancreatic cancer mortality trends since the middle of the twentieth century until recent years in Spain, using joinpoint regression models and age-period-cohort analyses to evaluate the independent effects of age, death period and birth cohort on these trends.

\section{Methods}

Mortality data for the calendar period 1952-2012 were obtained from the Spanish National Statistics Institute (Instituto Nacional de Estadística) at national level. During this period, different revisions of the International Classification of Diseases (ICD) have been used. Codes selected to identify deaths due to pancreatic cancer were adapted accordingly: code 157 in the ICD-6 to ICD-9 and code $\mathrm{C} 25$ in the ICD-10. Population data corresponding to censuses and municipal rolls for the midyear of each quinquennium were also obtained from the Spanish National Statistics Institute.

From 1975 to 2012, mortality and population data are public and available at regional level, and were stratified by sex, five-year-age group (from 0 to 4 to $85+$ years), calendar year and region (Autonomous Community). Age-adjusted mortality rates (AAMR) per 100,000 person-years were then calculated, by the direct method, for each sex, five-year calendar period and region, using the 1976 European Standard Population (ESP). Age-adjusted mortality rates were also calculated using the 2013 ESP to allow comparison with other works (Additional files 1 and 2) [10]. Additionally, annual age-adjusted mortality rates and their corresponding standard errors were calculated to study time trends for each region and sex. We used the joinpoint regression analysis to evaluate the presence of change points in adjusted mortality rates over time by sex and region and to estimate the annual percent of change over the study period [11]. Ceuta and Melilla regions were excluded from this analysis, because of their small populations.

With respect to age-period-cohort models, first, age-specific mortality rates per 100,000 person-years were computed by sex and calendar period (using five-year periods) at the national level. Then, separate log-linear Poisson models were fitted to study the effect of age, period of death and birth cohort for each sex on mortality trends. To address the "non-identifiability" problem (i.e. the three factors -age, period and cohort- are linearly dependent), we used Osmond and Gardner's solution [12], as well as curvature effects and net drift as proposed by Holford [13]. The Osmond-Gardner solution splits net drift into cohort and period slopes, by minimizing any disagreement in parameter estimates between the full three-factor model and each of the two-factor models (age-period, age-cohort and period-cohort) according to their goodness of fit. Moreover, it allows to estimate two parameters not affected by the non-identifiability problem: (i) overall change over time (denominated net drift), which is the sum of the cohort and period slopes [13]; and (ii) deviation of any period or cohort estimates from the general trend (denominated curvature). Age groups < 30 years were excluded from this analysis due to the limited number of deaths. The open-ended category of persons aged 85 years and over was also excluded. We checked for extra-Poisson dispersion [14] and, where present, effects were calculated using a negative binomial distribution.

The presence of change points and 95\% confidence intervals in the curvatures of the cohort and period effects was evaluated by fitting segmented models to the relationship between curvature effects and time. Details of the recursive algorithm used to estimate the segmented regression have been published elsewhere [15], and the procedure can be easily fitted using the R package "segmented" [16].

\section{Results}

As a geographic reference, Fig. 1 shows the location of the Spanish Autonomous Communities, with the regional distribution of pancreatic cancer mortality in both sexes in the last quinquennium (2008-2012). AAMRs (1976 ESP) by sex, Autonomous Community and calendar period are presented in Table 1. AAMRs have increased in both sexes in all regions, but not uniformly. The largest increases occurred before the 1990s in both sexes. Then, pancreatic cancer mortality rates have increased at a slower speed. No differences in this trend were observed between men and women. In both sexes, the highest increment took place between the 1978-1982 and the 1983-1987 quinquennia ( $18 \%$ in men and $23 \%$ in women), with more 


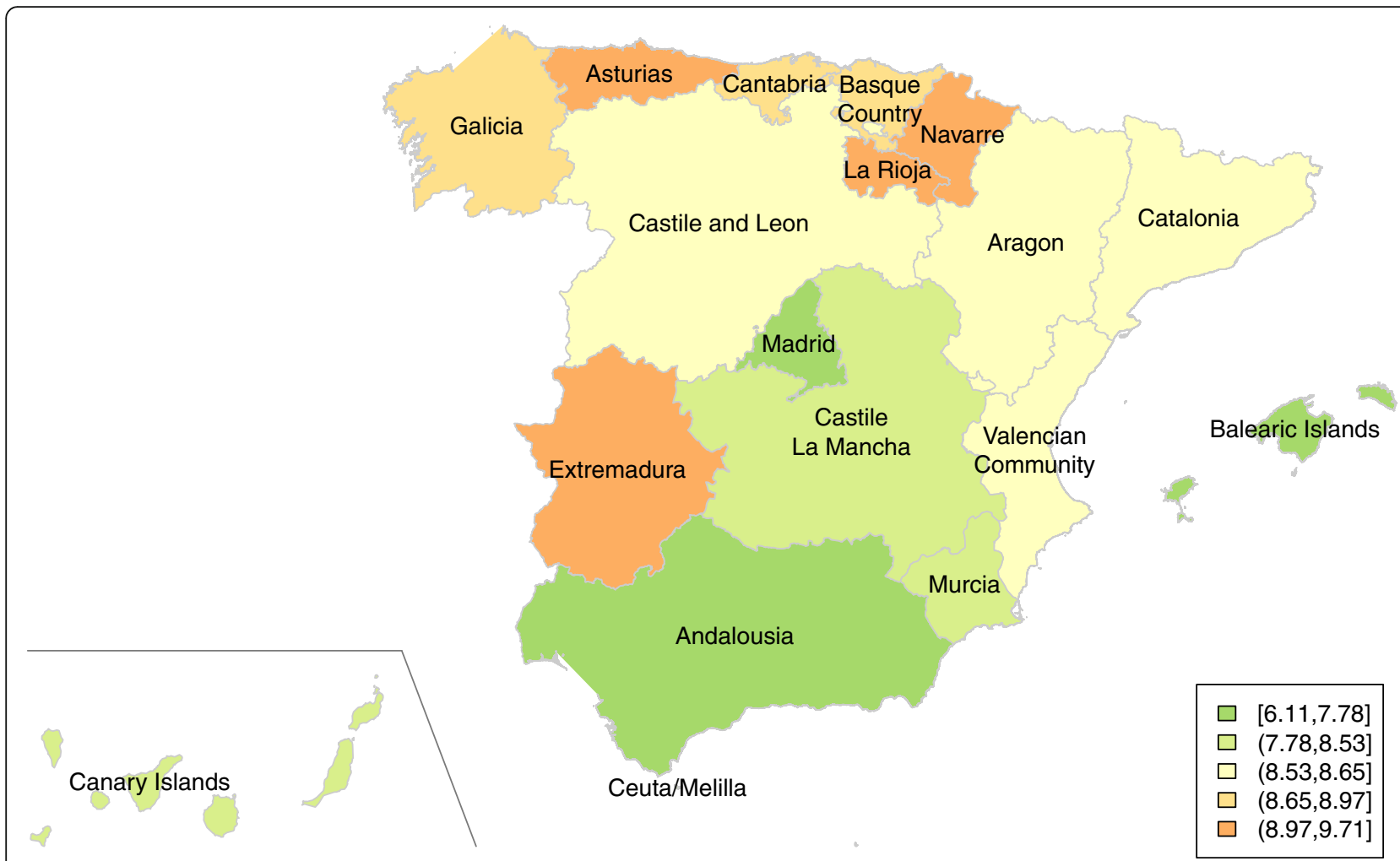

Fig. 1 Pancreatic cancer mortality in Spain (2008-2012): AAMR per 100,000 person-years (1976 ESP) by Autonomous Community

modest increments thereafter (between 5 and 11\%). Differences among regions over the study period have been slightly reduced: while in the quinquennium 1978-1982 the ratio between the highest and lowest rates was around 1.8 in males and 1.7 in females, in 2008-2012 this ratio was around 1.3 in both sexes. In men, the highest rates in the quinquennium 2008-2012 were found in Asturias, La Rioja and Galicia, whereas in women the highest rates corresponded to Navarra, Asturias and Cantabria. Since a new European Standard Population has been published recently, AAMRs were recalculated using the 2013 ESP (Additional file 1: Figure S1 and Additional file 2: Table S1). Results are similar, though AAMRs tend to be higher when using the 2013 ESP, given the greater weight that this new standard population gives to older age groups.

The results from joinpoint regression analyses over the period 1975-2012 by Autonomous Community and sex, and in Spain as a whole are presented in Table 2. Both in men and women statistically significant upward trends were seen in nearly all Autonomous Communities. In men, there was an overall increase in the rates of $2 \%$ per annum. Joinpoint analysis detected a change point in the mid-1980s: during the first period, rates increased by $4.1 \%$ per annum and by $1.1 \%$ during the second period. In women, pancreatic cancer mortality rates experienced a marked increase of $3.6 \%$ per annum from 1975 until the late 1980 s, and then increased by $1.4 \%$ per annum from 1987 to the end of the study period. By region, some of them also showed a two-phase pattern, although with differences in the year when the change was estimated to have occurred. Meanwhile, in others no inflection points were detected and rates increased at the same speed through the study period. Asturias was the Autonomous Community with the smaller overall increase (the only one under 1\%) in both sexes, though their mortality rates were among the highest of the country in all quinquennia. Figure 2 shows the evolution of smoothed pancreatic cancer death rates over time by sex and region. The presence of changes in trends is visible.

Figure 3 depicts age-specific rates by birth cohort, in men and women. In both sexes, clear increases over time are observed in all age groups over 45 years of age. However, in males younger than 45 years of age a trend to stabilization, or even a reduction, is observed, while among women this trend to stabilization is only observed for the 30-35 age group. Nevertheless, trends in the youngest age groups are based on a small number of deaths.

Table 3 presents the goodness of fit of the different age-period-cohort models. In men, period effect was the main contributor to the estimated trend in mortality, while in women the main contributor was the cohort effect. Figure 4 depicts cohort and period effects with the change 
Table 1 Pancreatic cancer mortality in Spain (1978-2012) by sex, Autonomous Community and calendar period ${ }^{2}$

\begin{tabular}{|c|c|c|c|c|c|c|c|c|}
\hline & & $1978-82$ & $1983-87$ & $1988-92$ & 1993-97 & 1998-02 & $2003-07$ & $2008-12$ \\
\hline \multirow[t]{20}{*}{ Men } & Andalucía & 5.34 & 6.18 & 6.71 & 7.37 & 7.57 & 8.29 & 9.34 \\
\hline & Aragón & 5.91 & 7.57 & 9.39 & 8.95 & 9.83 & 10.38 & 11.17 \\
\hline & Asturias & 8.81 & 11.67 & 10.26 & 9.79 & 11.10 & 11.64 & 12.37 \\
\hline & C.Valenciana & 6.33 & 7.84 & 7.71 & 8.45 & 9.33 & 9.04 & 10.60 \\
\hline & Cantabria & 7.88 & 9.49 & 10.78 & 10.74 & 10.33 & 11.79 & 10.81 \\
\hline & Castilla y León & 6.43 & 7.36 & 8.39 & 9.38 & 9.06 & 10.46 & 10.59 \\
\hline & Castilla-la Mancha & 4.86 & 5.96 & 6.78 & 7.18 & 7.74 & 8.68 & 9.26 \\
\hline & Cataluña & 6.91 & 8.34 & 8.95 & 9.67 & 9.44 & 10.07 & 10.79 \\
\hline & Ceuta & 5.14 & 10.31 & 11.69 & 14.56 & 13.21 & 13.66 & 9.54 \\
\hline & Extremadura & 6.18 & 6.86 & 9.18 & 8.86 & 10.50 & 9.80 & 11.36 \\
\hline & Galicia & 5.90 & 8.14 & 8.54 & 9.70 & 10.85 & 10.99 & 11.47 \\
\hline & Islas Baleares & 6.57 & 7.89 & 9.17 & 7.99 & 9.38 & 9.81 & 9.57 \\
\hline & Islas Canarias & 9.26 & 9.30 & 10.77 & 9.66 & 10.38 & 10.55 & 10.21 \\
\hline & La Rioja & 7.77 & 8.01 & 10.43 & 9.67 & 9.08 & 10.46 & 12.17 \\
\hline & Madrid & 5.93 & 5.76 & 7.99 & 7.92 & 9.31 & 9.52 & 9.19 \\
\hline & Melilla & 1.68 & 2.09 & 0.87 & 3.77 & 8.49 & 8.34 & 8.39 \\
\hline & Murcia & 6.16 & 6.33 & 6.48 & 7.73 & 9.06 & 9.66 & 10.21 \\
\hline & Navarra & 6.49 & 8.25 & 9.89 & 10.98 & 11.37 & 10.87 & 11.30 \\
\hline & País Vasco & 7.28 & 8.89 & 9.49 & 10.74 & 10.42 & 10.65 & 10.75 \\
\hline & Spain & 6.33 & 7.49 & 8.31 & 8.81 & 9.32 & 9.77 & 10.32 \\
\hline \multirow[t]{20}{*}{ Women } & Andalucía & 3.41 & 4.11 & 4.37 & 4.75 & 4.72 & 5.02 & 5.97 \\
\hline & Aragón & 3.83 & 4.85 & 5.14 & 6.01 & 5.87 & 6.33 & 6.37 \\
\hline & Asturias & 5.27 & 6.51 & 5.80 & 6.02 & 6.03 & 6.71 & 7.26 \\
\hline & C.Valenciana & 3.17 & 4.37 & 4.75 & 5.34 & 5.45 & 6.03 & 6.69 \\
\hline & Cantabria & 4.34 & 5.44 & 6.52 & 8.17 & 5.97 & 7.19 & 7.14 \\
\hline & Castilla y León & 3.57 & 4.61 & 4.74 & 5.35 & 5.69 & 5.77 & 6.81 \\
\hline & Castilla-la Mancha & 3.12 & 3.75 & 4.87 & 4.69 & 4.89 & 5.75 & 6.53 \\
\hline & Cataluña & 3.97 & 4.80 & 5.21 & 5.28 & 5.88 & 6.12 & 6.69 \\
\hline & Ceuta & 6.39 & 7.07 & 7.90 & 6.99 & 8.08 & 6.28 & 4.56 \\
\hline & Extremadura & 4.18 & 4.12 & 4.92 & 5.55 & 5.39 & 6.15 & 6.88 \\
\hline & Galicia & 3.35 & 4.36 & 4.50 & 5.47 & 5.89 & 6.16 & 6.58 \\
\hline & Islas Baleares & 3.52 & 4.44 & 4.95 & 5.77 & 5.58 & 5.98 & 6.01 \\
\hline & Islas Canarias & 3.74 & 5.06 & 6.24 & 6.42 & 6.58 & 6.91 & 6.69 \\
\hline & La Rioja & 4.46 & 5.57 & 5.53 & 5.44 & 6.95 & 6.27 & 6.61 \\
\hline & Madrid & 3.19 & 3.48 & 4.49 & 5.09 & 5.61 & 5.84 & 6.47 \\
\hline & Melilla & 3.45 & 1.25 & 3.63 & 5.18 & 4.28 & 2.97 & 2.46 \\
\hline & Murcia & 4.51 & 3.59 & 4.03 & 5.08 & 4.99 & 5.46 & 6.64 \\
\hline & Navarra & 3.86 & 5.28 & 5.12 & 6.49 & 6.69 & 6.97 & 8.18 \\
\hline & País Vasco & 3.86 & 5.25 & 5.74 & 5.81 & 6.47 & 6.44 & 6.80 \\
\hline & Spain & 3.64 & 4.46 & 4.89 & 5.36 & 5.61 & 5.96 & 6.57 \\
\hline
\end{tabular}

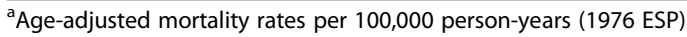


Table 2 Pancreatic cancer mortality trend changes in Spain evaluated using joinpoint analysis by sex and Autonomous Community

\begin{tabular}{|c|c|c|c|c|c|c|c|}
\hline & & & & Period 1 & & Period 2 & \\
\hline & & APC & N. of change points & Years & $\overline{\mathrm{APC} 1}$ & Years & APC 2 \\
\hline Men & Andalucía & $2.89^{\mathrm{a}}$ & 1 & $1975-1978$ & 17.66 & $1978-2012$ & $1.68^{\mathrm{a}}$ \\
\hline & Aragón & $1.71^{\mathrm{a}}$ & 0 & - & - & - & - \\
\hline & Asturias & $0.84^{\mathrm{a}}$ & 0 & - & - & - & - \\
\hline & C. Valenciana & $2.14^{\mathrm{a}}$ & 1 & 1975-1985 & $4.77^{\mathrm{a}}$ & $1985-2012$ & $1.19^{\mathrm{a}}$ \\
\hline & Cantabria & $0.84^{\mathrm{a}}$ & 0 & - & - & - & - \\
\hline & Castilla y León & $1.93^{\mathrm{a}}$ & 1 & 1975-1990 & $3.39^{\mathrm{a}}$ & 1990-2012 & $0.95^{\mathrm{a}}$ \\
\hline & Castilla-la Mancha & $2.00^{\mathrm{a}}$ & 0 & - & - & - & - \\
\hline & Cataluña & $1.79^{\mathrm{a}}$ & 1 & 1975-1987 & $3.90^{\mathrm{a}}$ & $1987-2012$ & $0.80^{\mathrm{a}}$ \\
\hline & Extremadura & $1.80^{\mathrm{a}}$ & 0 & - & - & - & - \\
\hline & Galicia & $2.82^{\mathrm{a}}$ & 1 & 1975-1985 & $6.93^{\mathrm{a}}$ & $1985-2012$ & $1.34^{\mathrm{a}}$ \\
\hline & Islas Baleares & $2.21^{\mathrm{a}}$ & 1 & 1975-1986 & $6.51^{\mathrm{a}}$ & $1986-2012$ & 0.45 \\
\hline & Islas Canarias & 2.37 & 1 & $1975-1978$ & 29.02 & $1978-2012$ & 0.30 \\
\hline & La Rioja & $1.38^{\mathrm{a}}$ & 0 & - & - & - & - \\
\hline & Madrid & $1.62^{\mathrm{a}}$ & 1 & $1975-2001$ & $2.50^{\mathrm{a}}$ & $2001-2012$ & -0.42 \\
\hline & Murcia & $1.74^{\mathrm{a}}$ & 0 & - & - & - & - \\
\hline & Navarra & $1.39^{\mathrm{a}}$ & 0 & - & - & - & - \\
\hline & País Vasco & $1.03^{\mathrm{a}}$ & 0 & - & - & - & - \\
\hline & Spain & $1.99^{\mathrm{a}}$ & 1 & 1975-1986 & $4.10^{\mathrm{a}}$ & $1986-2012$ & $1.11^{\mathrm{a}}$ \\
\hline Women & Andalucía & $1.57^{\mathrm{a}}$ & 0 & - & - & - & - \\
\hline & Aragón & $1.71^{\mathrm{a}}$ & 0 & - & - & - & - \\
\hline & Asturias & $0.94^{\mathrm{a}}$ & 0 & - & - & - & - \\
\hline & C. Valenciana & $2.78^{\mathrm{a}}$ & 1 & 1975-1984 & $6.48^{\mathrm{a}}$ & $1984-2012$ & $1.61^{\mathrm{a}}$ \\
\hline & Cantabria & $2.23^{\mathrm{a}}$ & 1 & 1975-1991 & $5.55^{\mathrm{a}}$ & $1991-2012$ & -0.23 \\
\hline & Castilla y León & $1.89^{\mathrm{a}}$ & 0 & - & - & - & - \\
\hline & Castilla-la Mancha & $2.34^{\mathrm{a}}$ & 0 & - & - & - & - \\
\hline & Cataluña & $1.52^{\mathrm{a}}$ & 0 & - & - & - & - \\
\hline & Extremadura & $1.65^{\mathrm{a}}$ & 0 & - & - & - & - \\
\hline & Galicia & $3.70^{\mathrm{a}}$ & 1 & 1975-1977 & 38.72 & $1977-2012$ & $1.99^{\mathrm{a}}$ \\
\hline & Islas Baleares & $1.54^{\mathrm{a}}$ & 0 & - & - & - & - \\
\hline & Islas Canarias & $1.76^{\mathrm{a}}$ & 1 & 1975-1992 & $3.64^{\mathrm{a}}$ & $1992-2012$ & 0.18 \\
\hline & La Rioja & 0.84 & 0 & - & - & - & - \\
\hline & Madrid & $2.55^{\mathrm{a}}$ & 1 & 1975-1994 & $3.61^{\mathrm{a}}$ & $1994-2012$ & $1.43^{\mathrm{a}}$ \\
\hline & Murcia & $1.65^{\mathrm{a}}$ & 0 & - & - & - & - \\
\hline & Navarra & $2.08^{\mathrm{a}}$ & 0 & - & - & - & - \\
\hline & País Vasco & $1.66^{\mathrm{a}}$ & 1 & 1975-1989 & $3.03^{\mathrm{a}}$ & $1989-2012$ & $0.84^{\mathrm{a}}$ \\
\hline & Spain & $2.09^{a}$ & 1 & 1975-1987 & $3.56^{\mathrm{a}}$ & $1987-2012$ & $1.39^{\mathrm{a}}$ \\
\hline
\end{tabular}

APC Annual Percentage of Change

${ }^{a}$ Statistically significant trend as obtained from the segmented regression. Statistical tests were two sided. The significance level was considered as 0.05

points (listed in Table 4) detected on their curvatures. With respect to the cohort effect in men, there was an increase in mortality until the generations born in the 1950s and a subsequent decline with a detectable change point around
1960. In women, as can be seen from its flatter curvature (thin line), the cohort effect is less pronounced and the change point was placed a decade later, though this finding is difficult to assess as it is based on very few 


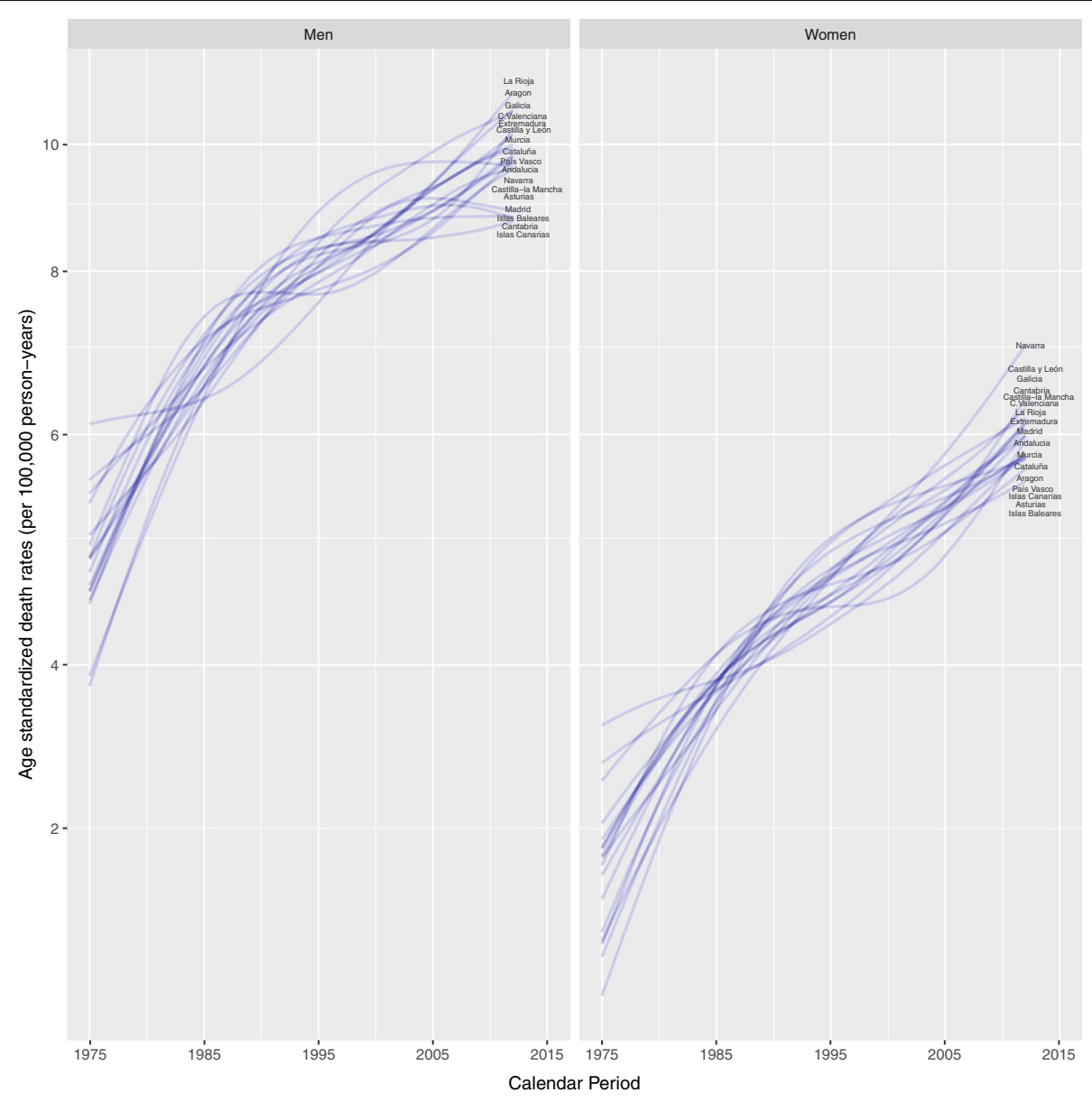

Fig. 2 Pancreatic cancer mortality trends in Spain (1975-2012), by sex and Autonomous Community. Age-adjusted smoothed mortality rates per 100,000 person-years (1976 ESP)

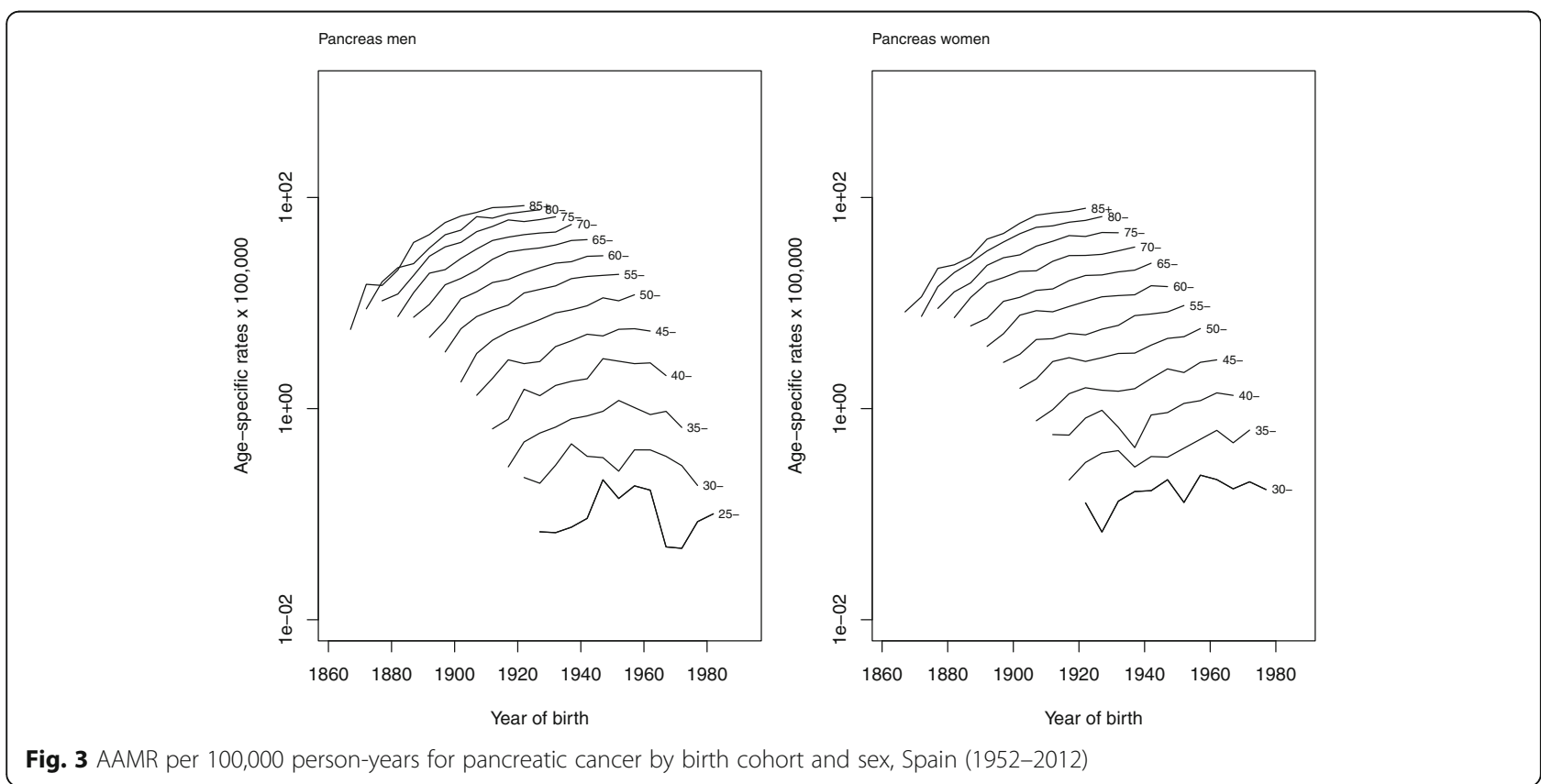

Fig. 3 AAMR per 100,000 person-years for pancreatic cancer by birth cohort and sex, Spain (1952-2012) 
Table 3 Goodness of fit in age, period and cohort models for pancreatic cancer mortality by sex, Spain (1952-2012)

\begin{tabular}{llll}
\hline & Degrees of freedom & Deviance & \% of change in deviance \\
\hline Men & 121 & & - \\
Age & 120 & 9980 & Reference \\
Age + drift & 110 & 1382 & $74.4 \%$ \\
Age + period & 100 & 354 & $63.2 \%$ \\
Age + cohort & 90 & 509 & $92.1 \%$ \\
Age + period + cohort & & 109 & - \\
Women & 121 & & \\
Age & 120 & 6094 & Reference \\
Age + drift & 110 & 694 & $52.9 \%$ \\
Age + period & 100 & 327 & $78.0 \%$ \\
Age + cohort & 90 & 82 & $88.2 \%$ \\
Age + period + cohort & & 153 & \\
\hline
\end{tabular}
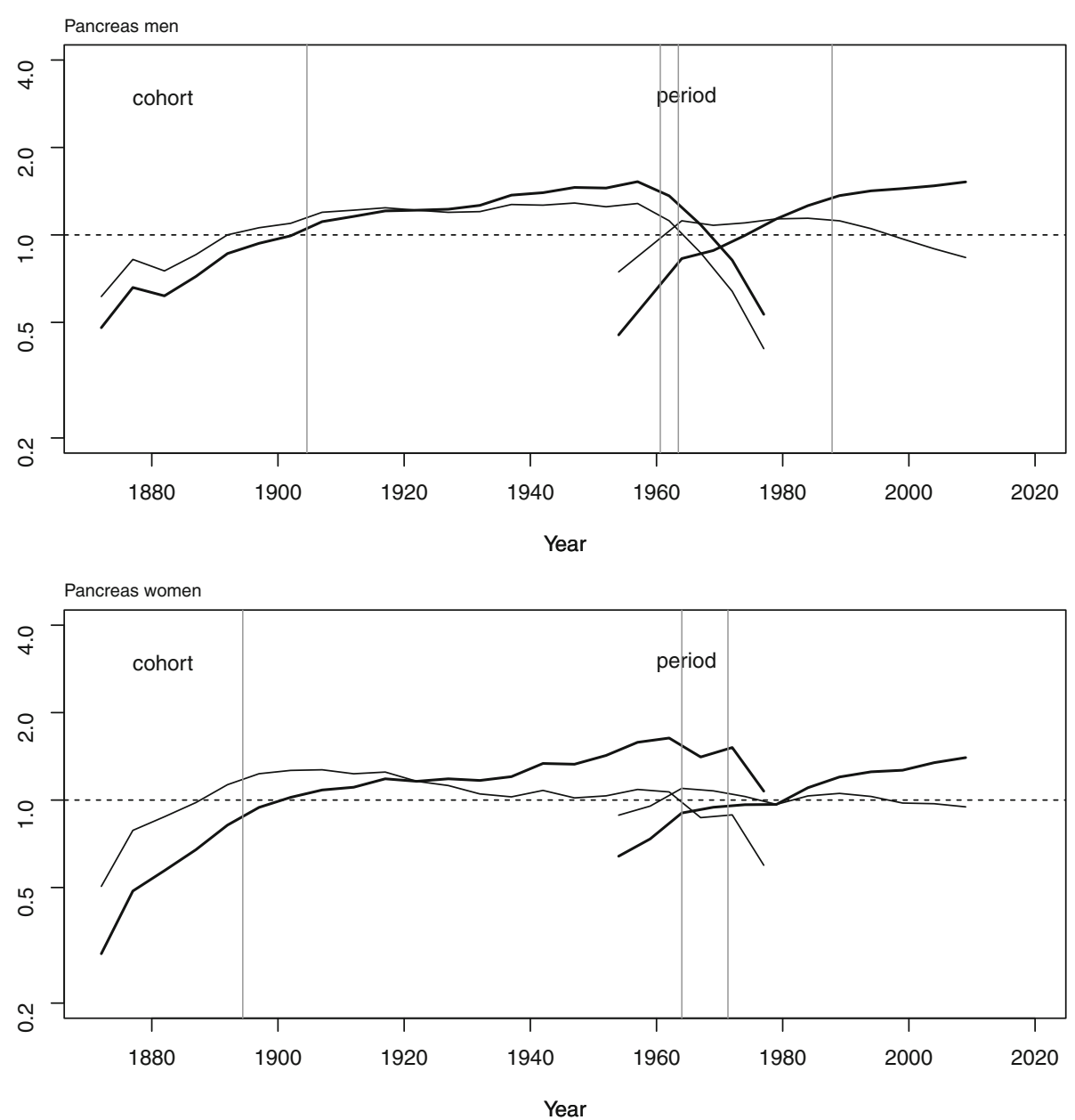

Fig. 4 Cohort and period effects on pancreatic cancer mortality by sex, Spain (1952-2012). Cohort and period effects (thick lines), curvature (thin lines) and change points in the curvatures (vertical grey lines) 
Table 4 Cohort and period effect curvature change-points on pancreatic cancer mortality by sex, Spain (1952-2012)

Changes in cohort effect ${ }^{a}$

\begin{tabular}{|c|c|c|}
\hline & $\begin{array}{l}\text { Birth year } \\
(95 \% \mathrm{Cl})\end{array}$ & $\begin{array}{l}\text { Birth year } \\
(95 \% \mathrm{Cl})\end{array}$ \\
\hline Men & $1904.6(1898.7-1910.5)$ & 1960.6 (1958.9-1962.3) \\
\hline \multirow[t]{3}{*}{ Women } & $1894.4(1890.9-1897.8)$ & $1971.2(1968.9-1973.6)$ \\
\hline & \multicolumn{2}{|c|}{ Changes in period effect ${ }^{\mathrm{b}}$} \\
\hline & $\begin{array}{l}\text { Year of death } \\
(95 \% \mathrm{Cl})\end{array}$ & $\begin{array}{l}\text { Year of death } \\
(95 \% \mathrm{Cl})\end{array}$ \\
\hline Men & 1963.5 (1961.7-1965.2) & $1987.83(1985.52-1990.14)$ \\
\hline Women & 1964.0 (1957.1-1970.9) & \\
\hline
\end{tabular}

${ }^{a}$ Year of birth with significant trend change as obtained from the segmented regression analysis of cohort curvatures from the three-factor model

${ }^{b}$ Year of death with significant trend change as obtained from the segmented regression analysis of period curvatures from the three-factor model

rates and deaths. For the period effect, there is a change in the general trend around 1962-1965 in both sexes, and a second change point in men around 1988, not visible in women.

\section{Discussion}

Our results show that pancreatic cancer mortality rates increased over the study period in Spain in both sexes and all regions. In general, this rise was similar in both sexes and in areas with higher and lower rates compared to Spain as a whole. In men, age-adjusted mortality rates annually grew on average by $4.1 \%$ in the period $1975-$ 86 , and by $1.1 \%$ between 1986 and 2012. In women there was a similar trend, with a bigger increase until the late 1980s (3.6\% annually between 1975 and 1987) than in the years after (1.4\% in the period 1987-2012).

The age-period-cohort analysis shows that, taking the mean rate for all cohorts as reference, the risk of dying from pancreatic cancer increased in generations born between 1870 and 1960 in men and women. This similarity in the trends could be related to changes in the exposure to risk factors linked to birth cohort and shared by both sexes. The rates observed in young men may indicate a levelling off in mortality in the most recent generations. Among women, this phenomenon is less clear, though the stabilization of the rates in the youngest age group could indicate that trend might soon parallel that of men.

For the period effect, there is a change in the general trend around 1962-1965 in males and females and a second change point in men around 1988. Though survival in pancreatic cancer is still very low, a slight improvement has been described in some countries in the last years [17-19], which could have contributed to the slower increase in the mortality rates since the 1990s observed in our study. The improvement in survival has been reported to be slightly higher in men [17]. This would be consistent with the different evolution in the period effect between men and women in the last years, with a lower annual increase of rates in men than in women since the 1990s.

In Europe, there are geographical differences in pancreatic cancer mortality trends. Mortality rates have increased in the last three decades in countries like France, Germany, Greece, Italy, Romania or Bulgaria, whereas in Sweden, the United Kingdom and Norway they have decreased (in the last two countries only in men). In Denmark, Ireland, Finland and Holland, mortality in men diminished until 1990s and then began to increase [20]. In the United States, white and black people show opposite trends: mortality rates in white men decreased from 1970 to 1995, and have increased since then; in white women, there was a slight increase between 1970 and 1984, a stabilization until the late 1990s, and an increase thereafter. On the other hand, in black men and women, rates increased until the late 1980s - early 1990s and have decreased since then [21]. In Canada, mortality rates between 1992 and 2009 declined in men and remained stable in women [22].

Understanding the reasons of the increase in pancreatic cancer mortality is challenging, given the complex and not well understood etiology of this neoplasm. In contrast with other cancer locations, like lung or cervical cancer, which are mainly associated with a unique risk factor, pancreatic cancer has been associated with multiple factors with modest effect sizes and, some of them, with high prevalence of exposure in the general population [6]. Probably, differences in latency periods among these factors may also have a different effect on pancreatic cancer trends, obscuring their specific contribution.

Among the risk factors for this cancer, the only universally accepted one is tobacco consumption [6]. Trends of pancreatic cancer mortality do not resemble those of other tumors strongly related to smoking, such as lung cancer, that is decreasing in males and increasing in females in Spain and in most developed countries. Nevertheless, the slower increase in pancreatic cancer mortality rates in the last decades could be influenced by the decreasing prevalence of tobacco consumption. In Spain, prevalence of smoking shows a decreasing trend in men since the late eighties (not previous data available), while in women, prevalence rose until the late nineties and then slightly decreased [23]. Accordingly, the continuous decrease of the rates in men cohorts born since the 1960s -not so evident in women-, could be related to the different evolution in the prevalence of smoking between sexes. Considering 2013 data, smoking prevalence in men over 34 years old had fell 9.8 percentage points in the last decade, while in women over 34 years old it had not decreased [24]. This would be consistent with a role of tobacco exposure in pancreatic cancer risk, but with the existence of other important contributing risk factors that would counterbalance the effect of the reduction in tobacco exposure. 
Another suspected risk factor for pancreatic cancer is Helicobacter pylori infection [6]. Again, trends of pancreatic cancer mortality do not resemble those of gastric cancer, strongly associated with this infection and whose mortality rates are decreasing in both sexes. Nevertheless, according to Fig. 4, the higher increase in the risk in cohorts born until the late nineteenth century-early twentieth century and the decrease in those born since the 1960 s or 1970 s in men and women, respectively, is congruent with the epidemiology of $H$. pylori infection. Though this effect is not as clear as it is in gastric cancer [25], which could be explained by a weaker association between $H$. pylori infection and pancreatic cancer, there seems to be some coincidence in time between both tumors, especially in women.

Though with limited evidence, other factors have been suggested to play a role in the etiology of pancreatic cancer. Among proposed risk factors, extensive research has focused on the role of diet and anthropometric factors $[26,27]$. As possible protective factors, a medical history of allergy, the consumption of fruits and vegetables, physical activity and parity have been suggested [6, 2831]. The controversial evidence from epidemiologic studies, the diverging trends of this broad spectrum of factors and the different prevalence of exposure among regions make it not easy to disentangle the specific role of each factor in pancreatic cancer trends.

A different aspect that could have played a role in the observed upward trend in pancreatic cancer mortality is the introduction of Computerized Tomography in Spain during the late 1970s of the twentieth century, and the spreading of its use during the 1980s. In this sense, advances in diagnosis and better death certification would have yielded a rise in the period effect. However, trends become less pronounced from the 1980s onwards.

This study has some advantages and limitations that should be taken into account. Among its strengths, it involves the follow-up of the total Spanish population through 60 years. This is a dynamic cohort, with entries and exits across the study period, which encompasses generations born approximately from 1865 to $1975-$ 1985 and thus constitutes a long time series. Also, survival of pancreatic cancer continues to be very low [2], and therefore, mortality statistics can be considered as a good proxy for incidence and are representative of the epidemiology of the disease. On the other hand, our results rely on the accuracy of death certificates and coding practices, and there could have been changes in their quality along the study period. However, cancer death certificates in Spain possess an accuracy comparable to that reported for other industrialized countries, and pancreatic cancer is among the cancer sites classified as well certified according to published quality indicators [32].

\section{Conclusions}

This study summarizes the trends in pancreatic cancer mortality in Spain, allowing for a detailed analysis of the influence of age, period and cohort effects in each sex. Like in other developed countries, pancreatic cancer mortality has been increasing over the last decades. However, differences have been identified between sexes. In men, mortality rates show a stabilization or even a decrease since the early 1990 s, mainly among post- 1960 birth cohorts, while in women, a stabilization in the trend is observable only among the youngest generations (born after the late 1970s). These differences may partially mirror the evolution of some established risk factors for pancreatic cancer, such as tobacco exposure, in men and women. Further research on the causes of pancreatic cancer is needed. In the meanwhile, recommendations to reduce exposure to preventable risk factors that have been associated with pancreatic cancer, such as tobacco smoking, obesity, diet and lack of physical activity may serve to reduce the impact of this and other chronic and malignant diseases.

\section{Additional files}

Additional file 1 Figure S1. Pancreatic cancer mortality in Spain (2008-2012): AAMR per 100,000 person-years (2013 ESP) by Autonomous Community. (PDF 529 kb)

Additional file 2 Table S1. Pancreatic cancer mortality in Spain. AAMR per 100,000 person-years (2013 ESP) by sex, Autonomous Community and calendar period. (DOCX $30 \mathrm{~kb}$ )

\section{Abbreviations}

AAMR: Age-adjusted mortality rates; ESP: European Standard Population; ICD: International Classification of Diseases

\section{Funding}

The study was funded by a research grant from the Spanish Health Research Fund (FIS PI11/00871). The funding body had no role in the design of the study and collection, analysis, and interpretation of data and in writing the manuscript.

\section{Availability of data and materials}

Data from the Spanish National Statistics Institute used in this study are public. For the calendar period 1952 to 1974, national population figures, together with number of deaths were obtained from the official annual reports of the National Statistics Institute. From 1975 to 2012, data are available on the Spanish National Statistics Institute website (http:// www.ine.es/dyngs/INEbase/listaoperaciones.htm). The datasets used and analysed during the current study are available from the corresponding author on reasonable request.

\section{Authors' contributions}

DSM analyzed and interpreted the data and drafted the manuscript. ON analyzed the data, formatted the figures and revised the manuscript. NFL, BPG and MP interpreted the results and revised the manuscript. GLA designed the study, analyzed and interpreted the results, formatted the figures and revised the manuscript. NA designed the study, interpreted the results and drafted the manuscript. All authors read and approved the final manuscript.

Ethics approval and consent to participate Not applicable. 


\section{Competing interests}

The authors declare that they have no competing interests.

\section{Publisher's Note}

Springer Nature remains neutral with regard to jurisdictional claims in published maps and institutional affiliations.

\section{Author details}

${ }^{1}$ Research Unit, Spanish Society of Rheumatology, Madrid, Spain. ${ }^{2}$ Cancer and Environmental Epidemiology Unit, National Center for Epidemiology, Carlos III Institute of Health, Madrid, Spain. ${ }^{3}$ Consortium for Biomedical Research in Epidemiology and Public Health (CIBER Epidemiología y Salud Pública, CIBERESP), Madrid, Spain.

Received: 14 December 2016 Accepted: 9 May 2018

Published online: 04 June 2018

\section{References}

1. Ferlay, J. et al. GLOBOCAN 2012 v1.0, Cancer incidence and mortality worldwide: IARC CancerBase No. 11 [Internet]. (International Agency for Research on Cancer, 2013)

2. De Angelis R, et al. Cancer survival in Europe 1999-2007 by country and age: results of EUROCARE-5-a population-based study. Lancet Oncol. 2014 15:23-34.

3. Instituto de Salud Carlos III. Mortalidad por Cáncer en España (2012). http:// www.isciii.es/ISCIII/es/contenidos/fd-servicios-cientifico-tecnicos/fd-vigilanciasalertas/fd-epidemiologia-ambiental-y-cancer/mortalidad-cancer-en-espana. shtml (2014).

4. López-Abente, G., Núñez, O., Pérez-Gómez, B., Aragonés, N. \& Pollán, M. La situación del cáncer en España: Informe 2015. (Centro Nacional de Epidemiología, 2015).

5. Hidalgo M. Pancreatic cancer. N Engl J Med. 2010;362:1605-17.

6. Maisonneuve $P$, Lowenfels AB. Risk factors for pancreatic cancer: a summary review of meta-analytical studies. Int J Epidemiol. 2015;44:186-98.

7. American Institute for Cancer Research. World Cancer Research Fund. Food, physical activity and the prevention of cancer: a global perspective. (AICR, 2007).

8. Ekbom A, Trichopoulos D. Pancreatic Cancer. In: Hans-Olov Adami, David Hunter, and Dimitrios Trichopoulos. In: Textbook of Cancer Epidemiology. Second ed. Oxford (United Kingdom): Oxford University Press; 2008.

9. Fritschi $\mathrm{L}$, et al. Occupational exposure to $\mathrm{N}$-nitrosamines and pesticides and risk of pancreatic cancer. Occup Environ Med. 2015;72:678-83.

10. Pace, M. et al. Revision of the European standard population. Report of the Eurostat's task force. (Publications Office of the European Union, 2013).

11. Kim HJ, Fay MP, Feuer EJ, Midthune DN. Permutation tests for joinpoint regression with applications to cancer rates. Stat Med. 2000:19:335-51.

12. Osmond C, Gardner MJ. Age, period and cohort models applied to cancer mortality rates. Stat Med. 1982;1:245-59.

13. Holford TR. Understanding the effects of age, period, and cohort on incidence and mortality rates. Annu Rev Public Health. 1991;12:425-57.

14. Breslow NE. Extra-Poisson variation in log-linear models. Appl Stat. 1984;33: 38-44.

15. Muggeo VM. Estimating regression models with unknown break-points. Stat Med. 2003;22:3055-71.

16. Muggeo VM. Segmented: segmented relationships in regression models. $R$ package version. 2004;0:1-4.

17. Søreide K, Aagnes B, Møller B, Westgaard A, Bray F. Epidemiology of pancreatic cancer in Norway: trends in incidence, basis of diagnosis and survival 1965-2007. Scand J Gastroenterol. 2010:45:82-92.

18. Lefebvre A-C, et al. Pancreatic cancer: incidence, treatment and survival trends-1175 cases in calvados (France) from 1978 to 2002. Gastroentérologie Clin Biol. 2009;33:1045-51.

19. Riall TS, et al. Pancreatic cancer in the general population: improvements in survival over the last decade. J Gastrointest Surg. 2006;10:1212-1223; discussion 1223-1224.

20. Bosetti C, et al. Cancer mortality in Europe, 2005-2009, and an overview of trends since 1980. Ann Oncol. 2013;24:2657-71.

21. Ma J, Siegel $R$, Jemal A. Pancreatic cancer death rates by race among US men and women, 1970-2009. J Natl Cancer Inst. 2013;105:1694-700.

22. Fung S, Forte T, Rahal R, Niu J, Bryant H. Provincial rates and time trends in pancreatic cancer outcomes. Curr Oncol. 2013;20:279-81.
23. Instituto Nacional de Estadística. Encuesta Nacional de Salud (serie histórica) Portal estadístico [Internet]. Ministerio de Sanidad, Servicios Sociales e Igualdad [cited 30/06/2017]. Available from: http://pestadistico. inteligenciadegestion.msssi.es/publicoSNS/Comun/ArbolNodos. aspx?idNodo $=42$.

24. Observatorio Español de la Droga y las Toxicomanías. Estadísticas 2015. Alcohol, tabaco y drogas ilegales en España [Internet]. Ministerio de Sanidad, Servicios Sociales e Igualdad. 2016 [cited 30/06/2017]. Available from: http://www.pnsd.msssi.gob.es/profesionales/sistemasInformacion/ informesEstadisticas/pdf/INFORME_2015.pdf.

25. Seoane-Mato D, et al. Trends in oral cavity, pharyngeal, oesophageal and gastric cancer mortality rates in Spain, 1952-2006: an age-period-cohort analysis. BMC Cancer. 2014;14:254

26. Shen Q-W, Yao Q-Y. Total fat consumption and pancreatic cancer risk: a meta-analysis of epidemiologic studies. Eur J Cancer Prev. 2015;24:278-85.

27. Genkinger JM, et al. Dairy products and pancreatic cancer risk: a pooled analysis of 14 cohort studies. Ann Oncol. 2014;25:1106-15.

28. Behrens $\mathrm{G}$, et al. Physical activity and risk of pancreatic cancer: a systematic review and meta-analysis. Eur J Epidemiol. 2015;30:279-98.

29. Farris MS, Mosli MH, McFadden AA, Friedenreich CM, Brenner DR. The association between leisure time physical activity and pancreatic Cancer risk in adults: a systematic review and meta-analysis. Cancer Epidemiol Biomark Prev. 2015;24:1462-73

30. Guan H-B, Wu L, Wu Q-J, Zhu J, Gong T. Parity and pancreatic cancer risk: a dose-response meta-analysis of epidemiologic studies. PLoS One. 2014;9: e92738.

31. Zhu B, et al. Parity and pancreatic cancer risk: evidence from a meta-analysis of twenty epidemiologic studies. Sci Rep. 2014;4:5313.

32. Pérez-Gómez B, et al. Accuracy of cancer death certificates in Spain: a summary of available information. Gac Sanit. 2006:20(Suppl 3):42-51.

\section{Ready to submit your research? Choose BMC and benefit from:}

- fast, convenient online submission

- thorough peer review by experienced researchers in your field

- rapid publication on acceptance

- support for research data, including large and complex data types

- gold Open Access which fosters wider collaboration and increased citations

- maximum visibility for your research: over $100 \mathrm{M}$ website views per year

At BMC, research is always in progress.

Learn more biomedcentral.com/submissions 